\section{Juan Rodés. A successful and extraordinary life of a visionary hepatologist}

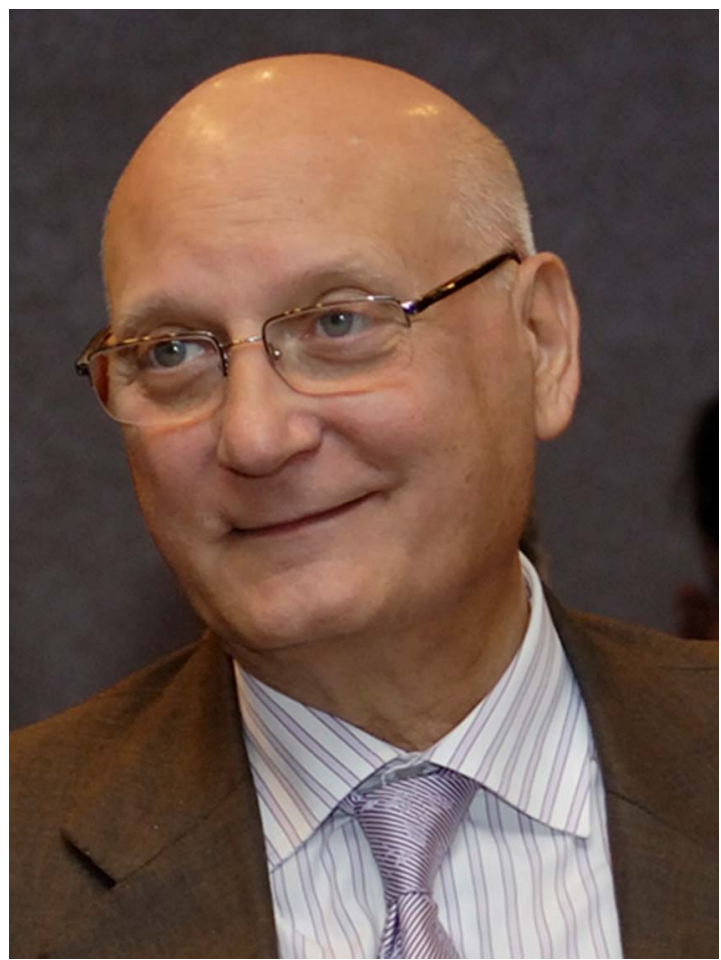

Dr Juan Rodés, architect of the Liver Unit of the Hospital Clinic of the University of Barcelona, an internationally renowned centre for research in liver disease, died in Barcelona on 10 January 2017, aged 78 years. He was one of the most inspiring and influential leaders in the field of clinical hepatology and the physician who changed modern medical practice in Spain.

Juan graduated from the University of Barcelona School of Medicine, Barcelona, in 1962, and trained in Internal Medicine at the Hospital Clinic. The centre has had the privilege of having Dr Rodés as Head of Hepatology Professor of Medicine, Director and Chief Executive Officer, till his retirement.

Dr Rodés and five other doctors started The Liver Unit informally in 1969 in the Catalan town of Montferri, Tarragona. Prior to this, Juan had completed a 1-year fellowship in Paris with Professor Caroli. From the beginning, each member of the unit was given charge of a specific area of liver disease. This was an excellent approach that resulted in the unit acquiring international prestige for the quality and breadth of its clinical research in hepatology. The unit participated actively at the meetings of the Spanish and International associations such as the European Association for the Study of the Liver, the American Association for the Study of Liver Diseases and the International Association for the Study of the Liver, and published the results of research in the top GI, Hepatology and Internal Medicine journals. Moreover, Juan served in two of these societies as President, and also as Editor-in-Chief of the
Journal of Hepatology. This was the result of the undisputed leadership of Juan Rodés, who together with his team at the Hospital Clinic was considered one of the most distinguished centres in the world for clinical hepatology. Thus, hundreds of physicians, mainly from Europe and Latin America, have spent short-term and long-term stints at the Liver Unit training in different aspects of hepatology.

Juan was extremely hard working throughout his career and displayed an incredible perseverance. He fought for knowledge and scientific values in his own work as a scientist and also in ensuring that these values permeated to decision and policy makers in society. The prestige of Juan Rodés far exceeded the scope of hepatology, since his visionary ideas represented a novel change in the way of understanding and practicing medicine and the crucial role of research training. In 1972, Juan played an essential role in the transformation of Hospital Clinic into a modern centre, which was organised into specialties. Moreover, he was one of the most prominent instigators of the 1-year fellowship grants that enabled advanced specialist trainees to initiate their first steps in research. Juan was also the driver for the sabbatical year, funded partially by the Hospital Clinic Medical Association, which permitted staff members of the hospital to expand their fields of interest in centres and labs outside Spain. Both programmes are still available today.

In the mid-80s, Dr Rodés set up the innovative Fundació Clinic and later the Institut d'Investigacions Biomèdiques August Pi Sunyer with a solid commitment to translational research. These structures have been mirrored by other departments of the Hospital Clinic and other hospitals across Spain. This has resulted in major improvements to what is now superb medical care and research in the country. In relation to this, Juan Rodés was heavily involved in the development of the Carlos III Health Institute and since 2001 he was the president of the board of medical experts of the Spanish Ministry of Health.

Over the years, Dr Juan Rodés was acknowledged with many national and international distinctions and awards from the medical associations and universities, as well as recognitions from the governments of Catalonia and Spain, such as the National Catalonian Research Award, the Sant Jordi Gold medal from the Generalitat de Catalunya, the Josep Trueta and Narcis Monturiol medals, the Spanish National Research Awards Gregorio Marañón and Severo Ochoa and the Great Cross of Civil Order of Health from Spain. But, most importantly, I believe the best recognition for Juan is the fact that the Spanish medical community acknowledges his profound and persistent efforts for the progress of hepatology and the practice of evidence-based medicine in Spain and across the world.

Juan is survived by his wife, Paula, and daughters Idoia and Claudia. We extend our sincere condolences to them. He will be deeply missed.

\section{Albert Pares*}

${ }^{*}$ On behalf of the Liver Unit.

Correspondence to Dr Albert Pares, Liver Unit, Hospital Clinic, University of Barcelona, 08036 Barcelona, Spain; pares@ub.edu

Competing interests None declared.

Provenance and peer review Not commissioned; internally peer reviewed. To cite Pares A. Gut Published Online First: [please include Day Month Year] doi:10.1136/gutjnl-2017-313950

Accepted 10 February 2017

Gut 2017;0:1. doi:10.1136/gutjnl-2017-313950 